\title{
Diagnostic and therapeutic challenges of hypercalcemia in a patient with localised breast cancer and primary hyperparathyroidism
}

Katharina Huss-Mischler ${ }^{1 *}$, Michael Schwitter ${ }^{1+}$, Michael Zoller ${ }^{2+}$, Rebecca Locher $^{3+}$ and Niklaus Kamber ${ }^{3+}$

*Correspondence: kaemi@gmx.ch

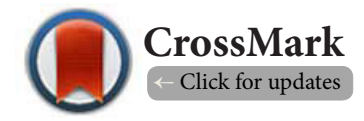

${ }^{\dagger}$ These authors contributed equally to this work.

'Dr. med., Clinic for oncology/hematology, Kantonsspital Graubünden, Chur, Switzerland.

${ }^{2}$ Dr. med., Clinic for nuclear medicine, Kantonsspital Graubünden, Chur, Switzerland.

${ }^{3}$ Dr. med., Clinic for endocrinology, Kantonsspital Graubünden, Chur, Switzerland.

\begin{abstract}
Incidental hypercalcemia is a common clinical problem with a broad differential diagnosis. Primary hyperparathyroidism and cancer are the two most common aetiologies. In addition to existing clinical symptoms, the assessment of duration and degree of hypercalcemia, as well as measuring of parathyroid hormone are crucial to distinguish between them. Usually the diagnosis is not difficult to make. However, on the basis of our patient with localised invasive triple-negative lobular breast cancer and concomitant primary hyperparathyroidism we demonstrate that the reality can be different. Despite the best and most modern technologies, both diseases can be difficult to diagnose. Accurate diagnostics are always important, but even more relevant for the correct staging and subsequent therapies in life-threatening tumours. An association between breast cancer and primary hyperparathyroidism is well known and has been described in many case reports. However, in the cases documented in the literature, the two illnesses occurred sequentially and not at the same time. Here, we highlight the diagnostic and therapeutic challenges of the simultaneous occurrence of the two diseases localised breast cancer and primary hyperparathyroidism, when hypercalcemia is the first clinical finding.
\end{abstract}

Keywords: Triple-negative invasive lobular breast cancer, primary hyperparathyroidism, hypercalcemia, osteoprotection

\section{Introduction}

Primary hyperparathyroidism (PHPT) and malignancy are responsible for more than $90 \%$ of all cases of hypercalcemia [1]. Malignancies can cause hypercalcemia because of bone metastases. However, hypercalcemia can also occur in nonmetastatic solid tumours, for example as a result of production of parathyroid hormone-related peptide. The first diagnostic step when hypercalcemia is found is confirmation of the hypercalcemia by repeated measurements of total calcium corrected for albumin and to synchronously measure parathyroid hormone. Furthermore, long-standing asymptomatic hypercalcemia and borderline or mild hypercalcemia are more suggestive of PHPT.

Previous studies have indicated that, independent of the histology, patients with breast cancer are subject to a higher incidence of PHPT [2]. Nevertheless, the frequency is comparable to the one in the general population before any breast cancer treatment [3]. The authors of the study concluded that the anti-cancer treatments should be taken into account for explaining the higher frequency of PHPT observed in treated breast cancer patients.

To our knowledge, the simultaneous diagnosis of PHPT and localised breast cancer based on the laboratory diagnosis of hypercalcemia has not been reported in the literature so far. The case presented here demonstrates in particular the difficulties of reaching a correct diagnosis.

\section{Case presentation}

The fifty-three-year-old premenopausal patient presented herself 
because of a palpated mass in her right breast. Furthermore, the patient felt more tired and was depressed, even with suicidal thoughts. Eleven years ago, she was diagnosed with a retinal melanoma which was cured by protonic radiation. The first diagnostic step was to perform a sonography guided core -biopsy. Hereby, the diagnosis of a locally advanced triple-negative invasive lobular breast cancer (ILBC) was made. The concurrently obtained laboratory result was remarkable as an albumin-corrected hypercalcemia of $2.92 \mathrm{mmol} / \mathrm{l}$ $(2.09-2.54 \mathrm{mmol} / \mathrm{l})$ was found. Former values were not available. The synchronously ordered parathyroid hormone revealed an elevated value of $26.2 \mathrm{pmol} / \mathrm{l}$ (1.6-6.9pmol/l).

For tumour-staging an 18F-fluorodeoxyglucosepositron emission tomography/computed tomography (PET-CT) was performed. This survey did not reveal any metastatic lesions but a locally advanced breast cancer (clinical T2, N2, M0). Furthermore, nephrolithiasis was found on both sides. Scintigraphy with $99 \mathrm{mTc}-$ Methoxy-Isobutyl-Isonitrile (MIBI) and a sonography did not help to localise the source of PTH excess. Finally, 18F-Choline PET-CT detected an isolated ectopic parathyroid adenomaposterior of the esophagus.

As a matter of fact, the two diagnoses of locally advanced invasive triple-negative breast cancer and PHPT could be achieved concomitantly.

The interdisciplinary tumour board decided to first treat the life-threatening cancer and then the PHPT. Because of stage and histology of the breast cancer neoadjuvant chemotherapy with Epirubicin and Cyclophosphamid (4 cycles every 3 week) followed by Paclitaxel ( 12 cycles every week) was initiated. This therapy showed a good tumour response before operation. Additionally, Cinacalcet was given to treat hypercalcemia. Serum calcium was lowered to the high normal range. The bone density was checked by an osteodensitometry and revealed an osteopenia with a minimal T-score at the lumbar spine of -1.8. The neoadjuvant chemotherapy over six months implied the concomitant use of repetitive steroids as an antiemetic and antiallergic drug. To prevent further loss of bone density, the patient received a bisphosphonate.

\section{Discussion}

ILBC is the most common special breast cancer subtype and represents about $5-15 \%$ of all invasive breast cancers. However, more than $95 \%$ of ILBC are hormone receptor-positive (estrogen receptor/progesteron receptor). Furthermore, ILBC is usually associated with older age at diagnosis, higher pathological tumour stage and higher percentage of bilateral, multifocal and multicentric cases. Furthermore, it is often presented with lower histological grade and low tumour cell proliferation [4]. Triple-negative ILBC is a very rare disease. It usually comes along with higher histological grade and a higher rate of cell proliferation. Treatment does not differ from ductal triple-negative breast cancer. Higher clinical T-stage qualifies for a neoadjuvant chemotherapy $[5,6]$.

As a common endocrine disorder of calcium metabolism,
PHPT is characterised by hypercalcemia with elevated or inappropriately normal concentrations of parathyroid hormone or high normal calcium level with elevated parathyroid hormone. In the large majority of cases PHPT is due to a benign overgrowth of parathyroid tissue and predominantly affects women. If scintigraphy with $99 \mathrm{mTc}-\mathrm{MIBI}$ is combined with sonography, a detection rate of $90 \%$ can be achieved [7]. In the cases where the localisation is impossible, it can mostly be detected by an $18 \mathrm{~F}$-Cholin PET-CT. Typical clinical presentation of PHPT is obvious skeletal, renal and gastrointestinal involvement. Nowadays, in many countries like the USA, Canada or Germany, a biochemical screening is implemented [8]. In these countries the most common presentation of PHPT is asymptomatic and mild, and patients can be observed. Candidates for surgery include young patients ( $<50$ years), renal indications like nephrolithiasis or nephrocalcinosis and renal insufficiency (Creatinin-Clearance $<60 \mathrm{ml} / \mathrm{min}$ ), skeletal indications like low bone density (osteoporosis with T-score $<-2.5$ ) and serum calcium concentration of $0.25 \mathrm{mmol} / \mathrm{l}$ or more above the upper limit of normal $[9,10]$.

Figure 1 illustrates the estimation of the probability of cancer or primary hyperparathyroidism based on the two most important differential diagnosis of hypercalcemia. Bone metastases were initially discussed as one cause for the combined occurrence of severe hypercalcemia with locally advanced breast cancer. With an unsuspicious 18F-FDG PET-CT and an elevated parathyroid hormone level the diagnosis of PHPT was obtained. 99mTc-MIBI scintigraphy and sonography revealed no adenoma. For localisation of the hyperfunctioning parathyroid tissue, further radiographic diagnostics were necessary. Luckily, Cholin-PET-CT was promptly available, so that - beside diagnosis of localised breast cancer - the hyperfunctioning parathyroid tissue causing the PHPT was detected.

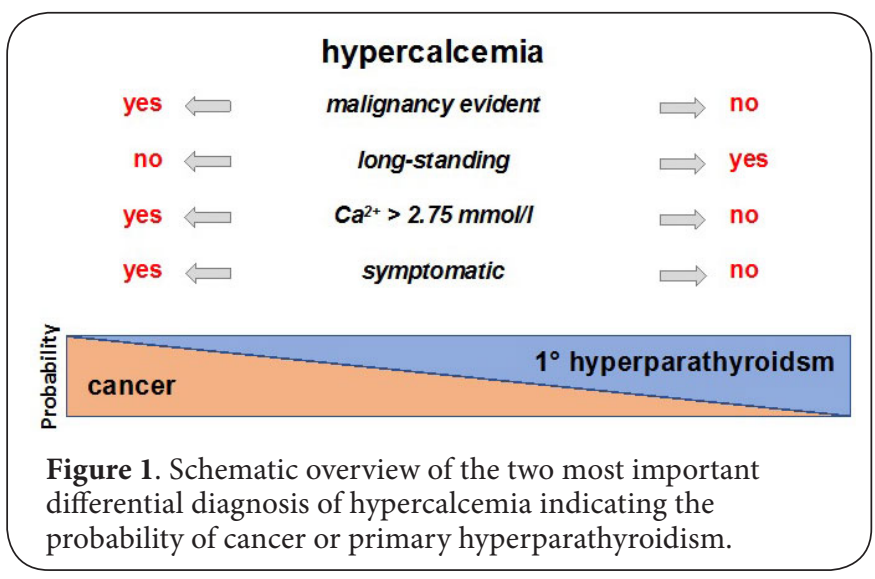

\section{Conclusions}

Although hypercalcemia is a common clinical problem, clarifying the cause is not always trivial. Especially when cancer as life-threatening disease is involved, precise diagnosis is extremely important, as correct tumour staging is necessary 
to initiate the right therapy. If that is complicated by the simultaneous occurrence of another difficult-to-diagnose disease, it represents a major clinical challenge. This case report emphasizes the importance of good teamwork between clinicians and disposable technology. It can only be speculated whether the sequence of diagnostic steps would have been the same if this clinical constellation was more common. That would require more similar cases. Further reports might describe other such cases thus contributing to a more comprehensive understanding of these diagnostic and therapeutic challenges.

\section{List of abbreviations}

PHPT: Primary hyperparathyroidism

ILBC: Invasive lobular breast cancer

PET-CT: Positron emission tomography/computed tomography MIBI: Methoxy-Isobutyl-Isonitril

Competing interests

The authors declare that they have no competing interests.

Authors' contributions

\begin{tabular}{|l|c|c|c|c|c|}
\hline Authors' contributions & KHM & MS & MZ & RL & NK \\
\hline Research concept and design & $\checkmark$ & $\checkmark$ & -- & -- & -- \\
\hline Collection and/or assembly of data & $\checkmark$ & $\checkmark$ & $\checkmark$ & $\checkmark$ & -- \\
\hline Data analysis and interpretation & $\checkmark$ & $\checkmark$ & $\checkmark$ & $\checkmark$ & -- \\
\hline Writing the article & $\checkmark$ & -- & -- & -- & -- \\
\hline Critical revision of the article & -- & $\checkmark$ & $\checkmark$ & $\checkmark$ & $\checkmark$ \\
\hline Final approval of article & $\checkmark$ & $\checkmark$ & $\checkmark$ & $\checkmark$ & $\checkmark$ \\
\hline Statistical analysis & $\checkmark$ & -- & -- & -- & -- \\
\hline
\end{tabular}

Publication history

Editor: Wei-Hsiung Yang, Mercer University School of Medicine, USA.

Received: 20-Mar-2020 Final Revised: 18-May-2020

Accepted: 28-May-2020 Published: 09-Jun-2020

\section{References}

1. Lafferty FW. Differential diagnosis of hypercalcemia. J Bone Miner Res. 1991; 6 Suppl 2:S51-9; discussion S61. | Article | PubMed

2. Tanaka Y. Primary hyperparathyroidism with breast carcinoma. Breast Cancer. 2010; 17:265-8. | Article | PubMed

3. Belardi V, Fiore E, Giustarini E, Muller I, Sabatini S, Rosellini V, Seregni $E$, Agresti R, Marcocci C, Vitti P and Giani C. Is the risk of primary hyperparathyroidism increased in patients with untreated breast cancer? J Endocrinol Invest. 2013; 36:321-5. | Article | PubMed

4. Christgen M, Steinemann D, Kuhnle E, Langer F, Gluz O, Harbeck N and Kreipe $\mathrm{H}$. Lobular breast cancer: Clinical, molecular and morphological characteristics. Pathol Res Pract. 2016; 212:583-97. | Article | PubMed

5. Loibl S, Volz C, Mau C, Blohmer JU, Costa SD, Eidtmann H, Fasching PA, Gerber B, Hanusch C, Jackisch C, Kummel S, Huober J, Denkert C, Hilfrich J, Konecny GE, Fett W, Stickeler E, Harbeck N, Mehta KM, Nekljudova $\mathrm{V}$, von Minckwitz $\mathrm{G}$ and Untch M. Response and prognosis after neoadjuvant chemotherapy in 1,051 patients with infiltrating lobular breast carcinoma. Breast Cancer Res Treat. 2014; 144:153-62. | Article | PubMed

6. Burstein HJ, Curigliano G, Loibl S, Dubsky P, Gnant M, Poortmans $P$, Colleoni M, Denkert C, Piccart-Gebhart M, Regan M, Senn HJ, Winer EP and Thurlimann B. Estimating the benefits of therapy for early-stage breast cancer: the St. Gallen International Consensus Guidelines for the primary therapy of early breast cancer 2019. Ann Oncol. 2019; 30:15411557. | Article | PubMed

7. Quak E, Blanchard D, Houdu B, Le Roux Y, Ciappuccini R, Lireux B, de Raucourt D, Grellard JM, Licaj I, Bardet S, Reznik Y, Clarisse B and Aide $\mathrm{N}$. F18-choline PET/CT guided surgery in primary hyperparathyroidism when ultrasound and MIBI SPECT/CT are negative or inconclusive: the APACH1 study. Eur J Nucl Med Mol Imaging. 2018; 45:658-666. | Article | PubMed Abstract | PubMed FullText

8. Bilezikian JP, Bandeira L and Khan A et al. Hyperparathyroidism. Lancet. 2018; 391:168-178.

9. Bilezikian JP, Brandi ML, Eastell R, Silverberg SJ, Udelsman R, Marcocc $\mathrm{C}$ and Potts JT, Jr. Guidelines for the management of asymptomatic primary hyperparathyroidism: summary statement from the Fourth International Workshop. J Clin Endocrinol Metab. 2014; 99:3561-9. | Article | PubMed Abstract | PubMed FullText

10. Silverberg SJ, Clarke BL, Peacock M, Bandeira F, Boutroy S, Cusano NE, Dempster D, Lewiecki EM, Liu JM, Minisola S, Rejnmark L, Silva BC, Walker MD and Bilezikian JP. Current issues in the presentation of asymptomatic primary hyperparathyroidism: proceedings of the Fourth International Workshop. J Clin Endocrinol Metab. 2014; 99:3580-94. | Article | PubMed Abstract | PubMed FullText

\section{Citation:}

Huss-Mischler A, Schwitter M, Zoller M, Locher R and Kamber N. Diagnostic and therapeutic challenges of hypercalcemia in a patient with localised breast cancer and primary hyperparathyroidism. Breast Cancer Rep. 2020; 7:2. http://dx.doi.org/10.7243/2057-1631-7-2 